\title{
RELATED PEDIATRIC DONORS - HEMATOPOIETIC STEM CELL COLLECTION
}

\author{
Valeria Ginani, Edna Goto, Adriana Seber \\ Correspondence to: vginani@uol.com.br
}

Hematopoietic stem cell (HSC) donation is considered a safe procedure and has been performed for more than 40 years. Particular attention should be paid to the donor and the donation process, considering both the safety of the donor and the recipient. Children may also be donors to their siblings, but with distinct peculiarities comparing to adult donation.

Several international accreditation committees monitor notifications of events and adverse reactions to donors participating in the registries worldwide. These committees periodically have published guidelines to ensure the health and well-being of these donors.

This topic will analyze the assessment of a donor under the age of 18 who has been identified as compatible with a sibling. The general issues involved in selecting donors for allogeneic HSCT will be discussed elsewhere in the consensus.

\section{DONOR ELIGIBILITY}

Unlike the unrelated donor, the family donor, even if he or she has certain diseases such as some autoimmune diseases, diabetes, or even localized cancers, may still be eligible for donation as long as the risk is acceptable ${ }^{2}$

The evaluation of the child as a donor should follow the same protocol used for the adult donor. In addition to the clinical history, the same evaluation tests are performed. If the recipient has a genetic disease like hemoglobinopathies, chronic granulomatous diseases, Fanconi anemia, among others, the sibling donor should be investigated for the same genetic condition.

\section{PSYCHOLOGICAL EFFECTS}

Children applying for HSC donation to their siblings, depending on their age, are unable to understand the act itself and are unable to voluntarily consent. Since the donation is considered safe for pediatric donors, there is a need to protect their mental and physical health differently from their sick sibling. ${ }^{3}$

A wide range of emotions related to the sibling donor experience has been reported. These include increased family closeness, improved relationships with the ill sibling, and a sense of tremendous pride in helping to save a life. Yet, negative responses for sibling donors have also been reported, including anxiety, depression, withdrawal, behavioral problems, anger, and responsibility for the transplant outcome. ${ }^{4,5}$

To minimize all the negative impacts of the donation procedure, the child donor should be evaluated by a specialized multidisciplinary team that at least the medical staff should be different from the one that takes care directly of the recipient to avoid the conflict of interest. In some countries, a kind of donor advocate has been determined, whose role would be to help parents and donors understand the medical procedure, as well as independently protect the interests and well-being of the donor. ${ }^{6}$

\section{CONDITIONS UNDER WHICH A MINOR MAY PARTICIPATE AS A HEMATOPOIETIC STEM CELL DONOR}

Worldwide, a person under 18 years old is not allowed to serve as a donor for a nonfamily member but may donate for a relative, most often a sibling. Currently, with the increased number of haploidentical transplants, a child or adolescent may be asked to donate to his or her sibling even to another relative.

In 2010, the American Academy of Pediatrics (AAP) published a policy statement regarding children as Hematopoietic stem cell donors. ${ }^{7}$ The AAP recommends five conditions that should be fulfilled for a minor to be a donor:

There is no medically equivalent histocompatibility adult relative who is willing and able to donate

There is a solid personal and positive relationship between the donor and recipient 
There is some likelihood that the recipient will benefit from transplantation

The clinical, emotional, and psychosocial risks to the donor must be minimized and reasonable in relation to the benefits expected to accrue to the donor and the recipient

Parental permission and donor assent (when possible) must be obtained

\section{JUDGE'S AUTHORIZATION}

In addition to the consent of parents and/or guardians, in Brazil, it is necessary to have a judge's authorization for a child to donate HSC to his or her sibling. ${ }^{8}$

\section{BONE MARROW DONATION}

The use of bone marrow from an HLA-identical sibling donor is considered the standard of care worldwide for children undergoing HSC transplantation. However, the number of allogeneic peripheral blood stem cells (PBSCs) among matched-sibling pediatric transplantations has increased recently. ${ }^{9}$

The European Group for Blood and Marrow Transplantation Pediatric Diseases Working Party published the experience of HSC collection in 453 pediatric donors, either bone marrow (BM) or PBCSs. ${ }^{9}$ They investigated prospectively factors influencing the safety of HSC collection in those donors. Bone marrow harvest is frequently complicated by mild to moderate pain, fatigue, and transient changes in peripheral blood cell count. They reported an increased risk of allotransfusion after BM harvest associated with a donor age of $<4$ years and a BM harvest volume of $>20 \mathrm{~mL} / \mathrm{kg}$ of the donor. In a multivariate logistic regression model, only donor/recipient weight ratio $<0.75$ was associated with an increased risk of cardiac complications, presumably due to the volume of marrow collected relative to donor size. Donor/recipient weight ratio $<0.75$ was also associated with a greater risk of post-donation anemia. Allogeneic blood transfusion in pediatric donors should be avoided unless an unexpected life-threatening event occurs, so the authors appointed that the BM harvest of $>20 \mathrm{~mL} / \mathrm{kg}$ is not an appropriate practice and should be discouraged. ${ }^{9}$

To minimize the most common complications of a bone marrow harvest in a young donor, it is recommended:

To start the iron supplementation with ferrous sulfate or equivalent (3 to $6 \mathrm{mg} / \mathrm{kg}$ elemental iron) one month before the day of collection and maintain one month after.

To have appropriate harvest needles for the size of the child

To collect autologous blood in children if there is an important discrepancy between donor and recipient body weight, two to three weeks before the BM harvest, and that the expected BM volume be superior of $20 \mathrm{ml} / \mathrm{kg}$ of the donor. But the procedure could be challenging due to the venous access, behavior of the child, and adequate material (needle size, bag etc)

To maintain appropriate analgesia during at least two to three days after the BM collection.

General anesthesia is recommended.

The bone marrow harvest is generally performed from the posterior iliac wing of the donor, about 2-3 $\mathrm{cm}$ below and laterally to the superior iliac spine. If it is necessary, the anterior iliac crest can be used, but the quantity that can be collected is clearly lower than that collected using the posterior iliac bone. ${ }^{10}$ Once the needle has passed the bone cortex, aspirations should be made by vigorous suction of not more than 5-10 $\mathrm{ml}$ of bone marrow using a heparinized syringe, and it is possible to rotate the needle when there is a large bezel or move the needle to always aspirate different sites of the bone marrow to minimize contamination with peripheral blood. Only one or two punctures are made in the skin in each side, but through this orifice, dozens of punctures are performed in the iliac bone. The aspirated product is then filtered and transferred into an anticoagulant solution, usually heparin and/or anticoagulant citrate dextrose formula-A (ACD). ${ }^{10}$

There are few studies using 3-5 days G-CSF prior to bone marrow harvest that shown an increased number of nucleated and CD34 cells collected, which resulted in more rapid engraftment but with no increased risk of graft versus host disease (GVHD). However, Chu et al. ${ }^{11}$ demonstrated the mortality risks were lower after transplantation of bone marrow compared to G-CSF primed bone marrow in adults with severe aplastic anemia (SAA), and the authors concluded that the bone marrow is the preferred graft for HLA matched sibling transplants for SAA. Therefore, additional randomized studies are needed to provide the optimal priming regimen and the benefit of G-CSF primed bone marrow collection, especially in a minor donor. 


\section{PERIPHERAL BLOOD PROGENITOR CELL (PBPC) COLLECTION}

The use of G-CSF for stem cell collection in pediatric donors is a very controversial issue. None of the rare early complications described in adults after G-CSF administration, like vascular events, splenic enlargement, or rupture, have been reported in children. The long-term effects of G-CSF use in healthy children have not been registered. In some European countries, the use of G-CSF is not routinely allowed in healthy children.

Eapen et al. ${ }^{12}$ showed that pediatric patients received no benefit from PBSC transplantation, and an even worse outcome was reported than bone marrow transplant, primarily because of chronic GVHD. Meantime, more recent data do not confirm this experience in the related scenario but instead support the finding that PBSC transplantation in children leads to faster engraftment without an increased risk of acute and/or chronic GVHD. ${ }^{13}$

Although several studies in adult donors have not demonstrated any increased long-term complications such as increased cancer risk after short-term G-CSF administration for PBSC, sufficient long-term studies in children addressing this issue have not been performed. ${ }^{14-16}$

The procedure of PBSC collection in children has the potential of causing pain related to G-CSF administration (site of administration and/or bone pain), the risks associated with central venous catheter (CVC) placement, the occurrence of hypocalcemia during apheresis, and the risk of cardiovascular complications related to hypovolemia. In addition, children with less than $20 \mathrm{~kg}$ may be exposed to heterologous red blood cells to prime an apheresis circuit of the machine.

For all above, the use of children as PBSC donors is still not recommended routinely.

However, if there is a significant difference between the weight of the donor and recipient and it was necessary to collect PBSC, some precautions must be taken, such as:

Venous access: younger pediatric donors may require central catheter placement for collection. Pulsipher et al. ${ }^{17}$ related that one-third of donors between ages 7 and 12 were successfully collected using peripheral access, but $97 \%$ of children under seven years needed a central venous line.

The catheter insertion should be performed with sedation or general anesthesia and by a well-trained staff. The site of the catheter insertion can vary according to the experience of the physician, but femoral vein catheterization has become an increasingly accepted method because of a lower complication rate during its insertion, especially when a rigid catheter is inserted. ${ }^{18}$

Complications of catheter placement are usually limited and mild. The most common is local pain. ${ }^{17}$ The thoracic vascular puncture may cause pneumothorax, hemothorax, pleural laceration, among other complications. The main immediate complications of femoral vein puncture are inadvertent arterial puncture (9 to 15\%) and hematoma (16\%), of easy clinical management. ${ }^{19,18}$

More recently, ultrasound-guided catheterization has considerably reduced the number of jugular vein puncture accidents in children, as demonstrated by Leyvi et al. ${ }^{20}$ Ultrasound, where available, should be used to guide vascular puncture also at other sites. ${ }^{21}$

\section{HYPOVOLEMIA:}

Children under $20 \mathrm{~kg}$ or when the extracorporeal machine volume of the circuit exceeds $10 \%$ to $15 \%$ of the total patient body volume, there is a significant risk of rapid decrease of hematocrit and pressure during an apheresis procedure, and the child may present hypotension, tachycardia, pallor and even hypovolemic shock. Therefore, it is an established practice in most centers to prime the apheresis machine with red blood cells or with $4 \%$ albumin solution. Orbach et al. ${ }^{22}$ described a protocol using priming with $4 \%$ albumin or high molecular weight hydroxethylstarch in children under $15 \mathrm{~kg}$. Before starting the procedure, red blood cell transfusion was performed in patients with hemoglobin below $12 \mathrm{~g} / \mathrm{dl}$. In total, $38 \%$ of patients did not require red blood transfusion, suggesting that this approach can avoid unnecessary transfusions. More recently, Norooznezhad et al. ${ }^{23}$ described their center's guideline for donors with less than $20 \mathrm{~kg}$. The donors received irradiated (25Gy), leukoreduced red blood cell transfusion if their hemoglobin level was less than $13 \mathrm{~g} / \mathrm{dL}$ at the night before the apheresis day. Moreover, the donors received 1:1 of the extracorporeal volume with normal saline 20-30 minutes at the beginning of the apheresis.

Japanese studies using regular donors less than 20 $\mathrm{kg}$ collected two or three $5-10 \mathrm{ml} / \mathrm{kg}$ autologous blood in sequential weeks before the PBSC harvest along with supplemental iron therapy. With this approach, they used only autologous blood priming for all their small donor. ${ }^{24}$ 


\section{ANTICOAGULANTS AND ELECTROLYTE DISORDERS:}

All leukapheresis procedures, including peripheral hematopoietic stem cell collection, require transient anticoagulation to prevent clot formation and system occlusion. The most used anticoagulant for leukapheresis is adenine citrate dextrose formula $A$ (ACD-A). Anticoagulation is due to the citrate and calcium complex formation, which causes the most frequently observed side effect, especially in children, the hypocalcemia. ${ }^{25,26}$ Probably, the reason that causes a higher frequency of hypocalcemia in younger children is that they have a lower hepatic metabolism of citrate. Signs and symptoms of hypocalcemia in children are generally nonspecific, and they could present as nausea, abdominal pain, agitation, hypotension, tachycardia, or even continuous crying. One option to reduce the risk of anticoagulant-related hypocalcemia is to infuse calcium in the patient in bolus or continuous infusion. Another option is to use only heparin for anticoagulation or the combination of heparin with ACD-A, but with a higher risk of bleeding. In addition to hypocalcemia, ACD-A can cause hypomagnesemia, hypopotassemia, and metabolic alkalosis. ${ }^{27,28}$ The study published by Bolan et al. ${ }^{29}$ thoroughly describes electrolyte changes observed in platelet donors during leukapheresis. The authors observed a ratio of serum citrate level and reduction of serum ionized calcium and magne-

\section{REFERENCES}

1. Szer J, Elmoazzen $H$, Fechter $M$, et al. Safety of Living Donation of Hematopoietic Stem Cells. Transplantation. 2016;100(6):1329-31. Available from: doi: 10.1097/TP.0000000000001223.

2. Worel N, Buser A, Greinix HT, et al. Suitability Criteria for Adult Related Donors: A Consensus Statement from the Worldwide Network for Blood and Marrow Transplantation Standing Committee on Donor Issues. Biol Blood Marrow Transplant. 2015 Dec;21(12):2052-2060. Available from: doi: 10.1016/j.bbmt.2015.08.009.

3. Bitan M, van Walraven SM, Worel N, et al. Determination of Eligibility in Related Pediatric Hematopoietic Cell Donors: Ethical and Clinical Considerations. Recommendations from a Working Group of the Worldwide Network for Blood and Marrow Transplantation Association. Biol Blood sium of $33 \%$ and $39 \%$, respectively, at the end of the procedure. They also observed a marked decrease in phosphorus. Total calcium and potassium levels decreased by $3 \%$ and $6 \%$, while sodium and bicarbonate increased by $1 \%$ and $3 \%$, respectively. Study data suggested that renal excretion of serum citrate overload causes increased renal excretion of cations, calcium, and magnesium. Increased renal excretion of potassium and sodium is likely to occur by metabolizing citrate to bicarbonate and continuous dextrose infusion from the anticoagulant solution. Therefore, to reduce the risks of electrolytes disturbances in a minor donor during leukapheresis, we suggest that children should receive an intravenous replacement of calcium, magnesium, and potassium.

\section{IN CONCLUSION:}

Most of the time, pediatric donors of hematopoietic stem cells can safely donate with parental consent and greatly benefit their recipients. They should be evaluated by a different and skilled medical staff to minimize their risks, the conflict of interest, and if there are increased risks of complications due to the collection, they should be deferred.

The use of G-CSF and heterologous red blood cell transfusion should be avoided in a child donor and when it is necessary to use, it should be discussed with the parents all the alternatives and risks.

Marrow Transplant. 2016;22(1):96-103. Available from: doi: 10.1016/j.bbmt.2015.08.017.

4. Wells RJ. The American Academy of Pediatrics policy statement--children as hematopoietic stem cell donors. Pediatr Blood Cancer. 2011;57(6):1086-7; author reply 1088-9. Available from: doi: 10.1002/pbc.23199.

5. Pentz RD, Alderfer MA, Pelletier W, et al. Unmet needs of siblings of pediatric stem cell transplant recipients. Pediatrics. 2014;133(5):e1156-62. Available from: doi: 10.1542/peds.2013-3067.

6. Wiener L, Hoag JA, Pelletier W, et al. Transplant center practices for psychosocial assessment and management of pediatric hematopoietic stem cell donors. Bone Marrow Transplant. 2019;54(11):1780-1788. Available from: doi: 10.1038/s41409-019-0515-3. 
8. American Academy of Pediatrics. Committee on Bioethics. Children as hematopoietic stem cell donors. Pediatrics. 2010;125(2):392-404. Available from: doi: 10.1542/peds.2009-3078. planalto.gov.br/ccivil_03/leis/l9434.htm

9. Styczynski J, Balduzzi A, Gil L, et al. Risk of complications during hematopoietic stem cell collection in pediatric sibling donors: a prospective European Group for Blood and Marrow Transplantation Pediatric Diseases Working Party study. Blood. 2012;119(12):2935-42. Available from: doi: 10.1182/blood-2011-04-349688.

10. Karakukcu M, Unal E. Stem cell mobilization and collection from pediatric patients and healthy children. Transfus Apher Sci. 2015;53(1):17-22. Available from: doi: 10.1016/j. transci.2015.05.010.

11. Chu R, Brazauskas R, Kan F, et al. Comparison of outcomes after transplantation of G-CSF-stimulated bone marrow grafts versus bone marrow or peripheral blood grafts from HLA-matched sibling donors for patients with severe aplastic anemia. Biol Blood Marrow Transplant. 2011;17(7):1018-24. doi: 10.1016/j. bbmt.2010.10.029.

12. Eapen M, Horowitz MM, Klein JP, et al. Higher mortality after allogeneic peripheral-blood transplantation compared with bone marrow in children and adolescents: the Histocompatibility and Alternate Stem Cell Source Working Committee of the International Bone Marrow Transplant Registry. J Clin Oncol. 2004;22(24):4872-80. Available from: doi: 10.1200/JCO.2004.02.189.

13. Remberger $M$, Ringdén $O$. Similar outcome after unrelated allogeneic peripheral blood stem cell transplantation compared with bone marrow in children and adolescents. Transplantation. 2007;84(4):551-4. Available from: doi: 10.1097/01.tp.0000275184.41831.6d.

14. Pulsipher MA, Chitphakdithai $P$, Logan BR, et al. Lower risk for serious adverse events and no increased risk for cancer after PBSC vs BM donation. Blood. 2014;123(23):3655-63. Available from: doi: 10.1182/blood-2013-12-542464.

15. Krejci M, Janikova A, Folber F, et al. Outcomes of 167 healthy sibling donors after peripheral blood stem cell mobilization with G-CSF $16 \mu \mathrm{g} / \mathrm{kg} /$ day: efficacy and safety. Neoplasma. 2015;62(5):787-92. Available from: doi: 10.4149/ neo_2015_094.
16. Schmidt AH, Mengling T, Hernández-Frederick CJ, et al. Retrospective Analysis of 37,287 Observation Years after Peripheral Blood Stem Cell Donation. Biol Blood Marrow Transplant. 2017;23(6):1011-1020. Available from: doi: 10.1016/j.bbmt.2017.02.014.

17. Pulsipher MA, Levine JE, Hayashi RJ, et al. Safety and efficacy of allogeneic PBSC collection in normal pediatric donors: the pediatric blood and marrow transplant consortium experience (PBMTC) 1996-2003. Bone Marrow Transplant. 2005;35(4):361-7. doi: 10.1038/sj.bmt.1704743

18. Moreiras-Plaza M, Albo C, Ares C. Efficacy and safety of femoral vascular access for peripheral blood stem cell (PBSC) collection. Bone Marrow Transplant. 2004;33(3):347-50. Available from: doi: $10.1038 /$ sj.bmt.1704357

19. Gallieni M, Pittiruti M, Biffi R. Vascular access in oncology patients. CA Cancer J Clin. 2008;58(6):323-46. Available from: doi: 10.3322/ CA.2008.0015.

20. Leyvi G, Taylor DG, Reith E, Wasnick JD. Utility of ultrasound-guided central venous cannulation in pediatric surgical patients: a clinical series. Paediatr Anaesth. 2005 Nov;15(11):953-8. Available from: doi: 10.1111/j.1460-9592.2005.01609.x.

21. Warkentine FH, Clyde Pierce M, Lorenz D, et al. The anatomic relationship of femoral vein to femoral artery in euvolemic pediatric patients by ultrasonography: implications for pediatric femoral central venous access. Acad Emerg Med. 2008;15(5):426-30. Available from: doi: 10.1111/j.1553-2712.2008.00087.x.

22. Orbach D, Hojjat-Assari S, Doz F, et al. Peripheral blood stem cell collection in 24 low-weight infants: experience of a single centre. Bone Marrow Transplant. 2003;31(3):171-4. Available from: doi: 10.1038/sj.bmt.1703825.

23. Norooznezhad AH, Malek Mohammadi A, Fumani HK, et al. Peripheral blood stem cell apheresis in low-weight children: A single centre study. Transfus Apher Sci. 2019;58(3):300-303. Available from: doi: 10.1016/j.transci.2019.04.018.

24. Kawano Y, Takaue Y, Watanabe T, et al. Efficacy of the mobilization of peripheral blood stem cells by granulocyte colony-stimulating factor in pediatric donors. Cancer Res. 1999;59(14):3321-4.

25. Bolan CD, Cecco SA, Wesley RA, et al. Controlled study of citrate effects and response to 
i.v. calcium administration during allogeneic peripheral blood progenitor cell donation. Transfusion. 2002;42(7):935-46. Available from: doi: 10.1046/j.1537-2995.2002.00151.x.

26. Sevilla J, González-Vicent M, Fernández-Plaza $S$, et al. Heparin based anticoagulation during peripheral blood stem cell collection may increase the CD34+ cell yield. Haematologica. 2004;89(2):249-51.

27. Bolan CD, Yau YY, Cullis HC, et al. Pediatric large-volume leukapheresis: a single institution experience with heparin versus citrate-based anticoagulant regimens. Trans- fusion. 2004;44(2):229-38. Available from: doi: 10.1111/j.1537-2995.2004.00668.x.

28. Humpe A, Riggert J, Munzel U, et al. A prospective, randomized, sequential crossover trial of large-volume versus normal-volume leukapheresis procedures: effects on serum electrolytes, platelet counts, and other coagulation measures. Transfusion. 2000;40(3):368-74. Available from: doi: 10.1046/j.1537-2995.2000.40030368.x.

29. Bolan CD, Greer SE, Cecco SA, et al. Comprehensive analysis of citrate effects during plateletpheresis in normal donors. Transfusion. 2001;41(9):1165-71. Available from: doi: 10.1046/j.1537-2995.2001.41091165.x. 